\title{
Lung Solute Permeability and Lung Liquid Absorption in Premature Ventilated Fetal Goats
}

\author{
EDMUND A. EGAN, ${ }^{(26)}$ ROBERT M. NELSON, AND ERNEST F. BEALE
}

Departments of Pediatrics, State University of New York at Buffalo; Childrens Hospital, Buffalo, New York; and University of Florida, Gainesville, Florida, USA

\begin{abstract}
Summary
In 21 premature fetal goats ventilated at low tidal volumes, measurements were made of alveolar surfactant activity by bubble stability tests on alveolar liquid, lung epithelium solute permeability using radiolabeled tracer molecules, lung liquid absorption from wet and dry lung weights, effectiveness of lung gas exchange, and lung mechanics. Arterial $\mathrm{pO}_{2}$ and residual gas volume were higher and arterial $\mathrm{pCO}_{2}$ and specific compliance were lower in animals whose bubble stability test was $>1: 5$ on alveolar liquid aspirated following one hr of ventilation. Animals without detectable surfactant in fetal lung liquid before ventilation had transfer of all size tracer solutes between alveolar liquid and blood, whereas those with detectable surfactant did not allow tracers $14 \AA$ or larger in radius to cross the lung epithelium. Lung liquid absorption rate in animals without lung liquid surfactant in fetal lung liquid before ventilation averaged $25 \% / \mathrm{hr}$, whereas those with surfactant absorbed liquid at only $2 \% / \mathrm{hr}$ in this protocol. All differences in solute permeability and lung liquid absorption were related to preventilation surfactant levels in fetal lung liquid, and not to postventilation surfactant levels or to lung function.
\end{abstract}

\section{Speculation}

These studies demonstrate that initiation of aeration of surfactant deficient fetal lungs at low tidal volumes causes abnormalities in the lung epithelium's normal barrier to large solutes. This may be the mechanism that allows plasma proteins to enter air spaces in human respiratory distress. Monotonous low tidal volume ventilation in animals with surfactant in fetal lung liquid resulted in retention of large volumes of alveolar liquid and suggested that occasional breaths of high tidal volumes are essential for normal lung liquid absorption.

\section{INTRODUCTION}

A newborn mammal in the first minutes after birth must establish effective pulmonary ventilation and simultaneously drain the lungs of the liquid that distends the air space of the fetal lung. Absorption of this liquid begins before ventilation in vaginally delivered animals $(3,6)$ due to inhibition of the active $\mathrm{Cl}^{-}$transport responsible for liquid secretion in the fetal lung $(22,24)$. Despite this process, newborns must absorb much, and those born by caesarian section without labor all of the fetal alveolar liquid while establishing ventilation.

In mature fetal lambs delivered by caesarian section, Egan $e$ t al. (13) described transient increases in the solute permeability of the alveolar epithelium accompanying lung liquid absorption during the first hr of spontaneous breathing. They proposed that the increase in the pore radius of the lung lining from $6 \AA$ in the fetal state to $40 \AA$ during the first hr of ventilation increased the conductance of the alveolar epithelial membrane to small solutes, which allows a more rapid rate of reabsorption, yet did not permit proteins from the interstitial space to contaminate alveolar fluid, thus preserving the protein concentration gradient between alveo- lar liquid and interstitium as an osmotic force for reabsorption. Investigation into the mechanism of this permeability change indicated that it resulted from the physical distention of the air space following aeration, and the degree of permeability increase was a function of the inflating force. This relationship between lung inflation and lung epithelial solute permeability has been reproduced in adult sheep (12).

In newborn infants with respiratory failure due to deficiency of pulmonary surfactant, the lungs retain larger amounts of water than expected (11), and the air spaces contain plasma proteins as hyaline membranes (14). We undertook to investigate the solute permeability of the alveolar epithelium and the drainage of alveolar liquid in immature, surfactant-deficient fetal goats to determine if these two abnormalities were causally related. Low-volume controlled ventilation was used so that we could avoid generalized overinflation of lung.

\section{METHODS}

We performed experiments on 21 fetal goats at gestational ages 118 to 140 days as determined by fetal roentgenograms at 90 to 100 days using the standard of Hessler (16). Nannies were anesthetized with $3 \mathrm{ml} / \mathrm{kg}$ of $3 \%$ Chloralose, the fetus was exteriorized from the uterus and tracheal and carotid artery cannulas were inserted, and arterial and airway pressure were recorded. The fetus was heparinized with 100 units $/ \mathrm{kg}$ of sodium heparin.

\section{LUNG LIQUID AND TRACERS}

Prior to ventilation, as much fetal lung liquid as possible was aspirated into a syringe, and $5 \mathrm{ml}$ were removed for assay. Trace amounts of 3 radiolabeled solutes of known molecular size were mixed with the aspirated lung liquid. One solute from each of the following three groups was used in each experiment: large solute, $\left[{ }^{131} \mathrm{I}\right]$ bovine albumin, molecular radius $35 \AA$; medium solutes, ${ }^{125} \mathrm{I}$ ovalbumin, molecular radius $17 \AA{ }^{125} \mathrm{I}$-cytochrome C, molecular radius $17 \AA ;\left[{ }^{3} \mathrm{H}\right]$ inulin, molecular radius $14 \AA$; small solutes, $\left[{ }^{57} \mathrm{Co}\right]$ cyanocobalamin, molecular radius $6 \AA ;\left[{ }^{14} \mathrm{C}\right]$ sucrose, molecular radius $5.1 \AA$.

$\left[{ }^{51} \mathrm{Co}\right]$ Cyanocobalamin, $\left[{ }^{3} \mathrm{H}\right]$ inulin, and $\left[{ }^{14} \mathrm{C}\right]$ sucrose were obtained from Amersham Corp., Arlington Heights, IL, or New England Nuclear, Boston, MA. Proteins were labeled by the method of MacFarlane (19) or using Bolton Hunter Reagent. Different medium and small solutes had to be used because of counting equipment breakdowns and mismatching of animal availability and tracer supply during the experimental period. Just prior to reinstillation of the lung liquid and tracers, $\left.{ }^{51} \mathrm{Cr}\right]$ hemoglobin, prepared by incubation of ${ }^{51} \mathrm{Cr}$ with lysed goat red blood cells, was injected into the fetal arterial system.

\section{EXPERIMENTAL PROCEDURE}

The fetal lung liquid with tracers was reinstilled into the lung and mixed for $30 \mathrm{~min}$ with the lung liquid still in the lung. After $30 \mathrm{~min}, 1.0 \mathrm{ml}$ samples of arterial blood and fetal lung liquid were 
collected. Ventilation was initiated with a piston-type small animal ventilator at a frequency of $20 / \mathrm{min}$ to deliver a volume of $8 \mathrm{ml} /$ $\mathrm{kg}$ at ambient temperature and peak airway pressure, based on an estimate of fetal weight. Following the experiments, actual weighing of the fetus revealed that tidal volumes averaged $8.9 \mathrm{ml} / \mathrm{kg}$ in the 21 animals with a range of 7 to $11 \mathrm{ml} / \mathrm{kg}$. All ventilation was with $100 \%$ oxygen and at 0 end expiratory pressure. At 15-min intervals, blood samples for $\mathrm{pH}$ and blood gases were taken, and ventilation was stopped. Support of the fetus continued via the umbilical circulation. The $\mathrm{O}_{2}$ was partially aspirated from the lung through the tracheal cannula into a syringe, and the remainder was absorbed by pulmonary blood flow, allowing us to sample residual liquid in the lung. A $1.0-\mathrm{ml}$ sample of lung liquid was taken, the rest of the lung liquid was reinfused, and ventilation was restarted. After the penultimate sample at 45 to $50 \mathrm{~min}$ of ventilation, the umbilical circulation was interrupted, and for the last $15 \mathrm{~min}$, all fetal gas exchange was lung dependent. At the last sample, stopping ventilation and closing the airway was followed by an asphyxial response, which was interrupted by $\mathrm{KCl}$ injection once lung liquid could be aspirated. Immediately following death, the thorax was opened, and an in situ, quasistatic, pressure-volume curve with air was performed on the lung. Maximum inspiratory pressure was $40 \mathrm{~cm} \mathrm{H}_{2} \mathrm{O}$, and volume was measured after $60 \mathrm{sec}$ at each pressure. The lungs were removed, weighed, and air-dried until weight was static for 2 days to obtain wet and dry weights.

\section{ANALYTIC PROCEDURES}

Lung liquid and blood samples were centrifuged and counted using a Packard Auto-Gamma Scintillation Spectrometer or beta scintillation techniques we have previously described $(12,13)$. In experiments using $\left[{ }^{131} \mathrm{I}\right]$ albumin, $\left[{ }^{3} \mathrm{H}\right]$ inulin, and $\left[{ }^{14} \mathrm{C}\right]$ sucrose, the ${ }^{131}$ I]albumin was counted immediately, and then the samples were allowed to wait 6 to $8 \mathrm{wk}$ for ${ }^{131} \mathrm{I}$ decay before the $\left[{ }^{3} \mathrm{H}\right]$ inulin and $\left[{ }^{14} \mathrm{C}\right]$ sucrose were counted. When multiple gamma-emitting tracers were used, spill of counts from one peak into others were corrected by a fourth-order matrix using single label standards for every experiment. Before lung liquid samples were centrifuged, pulmonary surface active material activity was assayed using the bubble stability test of Clements et al. (9) starting at 1:1 dilution and serially diluting samples to $1: 5$.

The 21 animals were divided into 4 groups based on the levels of surfactant in alveolar liquid both before and after the hr of ventilation. Only group 1 animals had surfactant present in both samples. Groups 2 and 3 had negative bubble stability tests before ventilation and were divided by whether postventilation levels were more than 1:5 (Group 2) or between 1:1 and 1:5 (Group 3). Group 4 animals had negative bubble stability tests before and after ventilation. This grouping resulted from the hypothesis that presence of surfactant at the initiation of breathing and the amount released during ventilation might be an important variable in the degree and evenness of aeration of alveoli and thus in solute permeability characteristics of the epithelial lining.

\section{CALCULATIONS}

In an unventilated fetal lung, solutes larger than $6 \AA$ in the lung liquid were totally restricted by the alveolar epithelium to the air space (20). Thus, we could obtain the volume of lung liquid in the fetal lung before ventilation from simple indicator dilution calculations using both the large and medium sized solutes from

$$
\mathrm{Vf}=\mathrm{VoCo} / \mathrm{Cf}
$$

where $\mathrm{Vf}$ is the volume of fetal lung liquid, $\mathrm{Cf}$ is the concentration of a tracer in Vf, Vo is the volume of lung liquid reinstilled after addition of the tracer, and Co is its concentration in Vo.

In three separate fetal experiments, we only measured fetal lung liquid volumes, sacrificed the animal, and measured wet weight: dry weight ratios of excised lung. We found that the dry weight was $22 \pm 1 \%$ of the total wet weight minus the weight of the alveolar fluid, identical to lung wet weight:dry weight ratios we measured on the lungs of 2 additional newborn kids 2 and 3 days after birth. Pulmonary blood volume is unchanged by initiation of ventilation $(1,3)$, and our measurements are similar to previous ones of the postnatal goat lung (5) and very close to newborn lambs whose lungs are $21.5 \%$ dry weight $(8)$. Thus, we presume that blood and interstitial and cellular water have the same quantitative relationships to dry weight in fetal and newborn animals.

To calculate absorbed lung liquid, we used the following formula:

$$
V a=V f-[L w-(L d / 0.22)]-\sum_{i=1}^{n} s_{i}
$$

where $\mathrm{Va}=$ volume absorbed, $\mathrm{Lw}$ is wet lung weight, $\mathrm{Ld}$ is dry weight, and $\sum_{i=1}^{n} s_{i}$ is the sum of lung liquid removed by experimental samplings. This calculation estimates clearance of alveolar fluid from the lung and assumes all "excess" liquid remains in the alveolar space. Because engorgement of interstitium occurs during absorption, this calculation underestimates alveolar liquid absorbed to some extent.

The capacitance of the lung interstitium for liquid above baseline in these animals is unknown. In dogs, interstitial liquid can increase about $100 \%$ before alveolar flooding (17). Extrapolation of that value to these experiments means that the lungs can contain $2 \mathrm{ml} / \mathrm{kg}$ body weight of additional liquid during lung drainage or less than $10 \%$ of initial alveolar liquid. However, Bland et al. (6) using only morphometric measurement report a capacitance of lung perivascular interstitial spaces which approximates the total volume of alveolar liquid in newborn rabbits. Although we find a capacitance of lung interstitium as large as this difficult to conceptualize, we cannot specify that undrained fetal lung liquid is primarily alveolar. However, a significant part must be alveolar because we could still aspirate alveolar liquid after one $\mathrm{hr}$ of ventilation.

Absorption of alveolar liquid solutes was calculated using the volumes absorbed from equation 2.

$$
\mathrm{Sa}=\mathrm{VfCf}-(\mathrm{Vf}-\mathrm{Va}) \mathrm{Cn}-\sum_{i=1}^{n} \mathrm{Vs}_{\mathrm{i}} \mathrm{Cs} s_{\mathrm{i}}
$$

where $\mathrm{Sa}$ is the amount of tracer absorbed, $\mathrm{Cn}$ is concentration in the nth samples, and $\sum_{i=1}^{n} V s_{i} C s_{i}$ is sum of the amounts removed by sampling (volume $\times$ concentration). Here, because $\mathrm{Va}$ is underestimated from equation 2 , there will be an underestimate of solute absorption dependent upon $\mathrm{Va}$.

We had originally sought to quantitate the movement of the macromolecule $\left[{ }^{51} \mathrm{Cr}\right.$ ]hemoglobin into lung liquid following ventilation by measuring the ratio of lung liquid and blood counts after one hr of ventilation. However, we were unable to achieve a high specific activity in our labeling of hemoglobin. The counts in the blood were small but high enough to measure accurately, however, the ${ }^{51} \mathrm{Cr}$ counts in lung liquid were only about 1 to $2 \%$ of the counts $/ \mathrm{ml} / \mathrm{min}$ of the three other gamma tracers. Because of inherently large standard errors of small counts and the fact that total counts in ${ }^{51} \mathrm{Cr}$ channel were largely spill from ${ }^{57} \mathrm{Co}$ and ${ }^{131}$ I emissions, our reproducibility of lung liquid ${ }^{51} \mathrm{Cr}$ counts was $\pm 50 \%$. We could detect with certainty whether $\left[{ }^{51} \mathrm{Cr}\right]$ hemoglobin was present in lung liquid at $1 \mathrm{hr}$, but a lung liquid/blood ratio of ${ }^{51} \mathrm{Cr}$ was not able to be determined with any accuracy.

Differences were compared by the Student $t$ test.

\section{RESULTS}

\section{SURFACTANT ACTIVITY AND LUNG FUNCTIONS}

Assay of amniotic fluid at hysterotomy showed a negative bubble stability test at a $1: 1$ dilution in all 21 fetuses. The fetal lung liquid bubble stability test was positive in 3 animals (range, $1: 2$ to $1: 5$ ) and negative at $1: 1$ on the remaining 18 . The $\mathrm{hr}$ of ventilation increased the surfactant activity in the 3 animals with 
detectable surfactant in fetal lung liquid, produced detectable activity in 14 other animals, and produced no activity in the remaining 4 animals.

In Table 1, the 21 animals are divided into 4 groups based upon the bubble stability test results before and after ventilation. As expected, the gestational ages and weights of the groups vary inversely with amount of surfactant detectable. The 10 animals in groups 1 and 2, those with bubble stability tests $\geq 1: 5$ at $1 \mathrm{hr}$, showed similar gas exchange and lung mechanics. Group 3, bubble stability test $1: 1$ to $1: 4$ at $1 \mathrm{hr}$, showed significantly poorer gas exchange and smaller lung expiratory volumes than groups 1 and 2 , but still better than the 4 animals in group 4 , who had negative bubble stability tests at $1 \mathrm{hr}$, no residual gas in the lung at expiration, and profound hypoxemia and hypercapnea. Compliance during ventilation and on the static pressure volume curve after the hour of ventilation was similar for groups 3 and 4 and significantly less than that in groups 1 and 2 .

The physiologic functions of gas exchange and lung function were related to the amount of surfactant in the alveolar space after ventilation not the amount present before ventilation.

\section{ABSORPTION OF LUNG LIQUID}

In Table 2, the measured fetal lung liquid volumes and lung weights and the calculated amount and rate of lung liquid drainage are presented for each group. In contrast to the measurements of gas exchange and lung mechanics, group 1 animals appeared to have very different lung liquid drainage than the other groups. Among the 3 groups who had negative bubble stability tests on fetal lung liquids, there were no significant differences. Despite the fact that the 3 animals in group 1 had less lung liquid before ventilation, the wet weight of the lung was greater, and their calculated lung liquid drainage was miniscule. Significant drainage of lung liquid was calculated for each of the other groups.

\section{SOLUTE MOVEMENT BETWEEN LUNG LIQUID AND BLOOD}

Table 3 summarizes solute movements in each group. In animals with surfactant present in fetal lung liquid before ventilation, group 1, we could not measure any loss of either the large- or medium-size solutes from alveolar lung liquid nor did they appear in blood. Neither could we detect any $\left[{ }^{51} \mathrm{Cr}\right]$ hemoglobin moving into the lung liquid. The calculated $3 \%$ loss of medium solute is not significantly different from 0 . In these 3 animals, solutes $14 \AA$ or larger appeared restricted by the alveolar epithelium from moving into or out of the alveolar liquid.

In all of the other groups, all solutes moved out of the alveolar space, and detectable levels were observed in blood samples. In addition, $\left[{ }^{51} \mathrm{Cr}\right]$ hemoglobin was present in lung liquid samples following ventilation, indicating the epithelium was permeant to

Table 1. Gas exchange and lung mechanics in premature goats grouped by alveolar liquid BST before and after ventilation

\begin{tabular}{|c|c|c|c|c|}
\hline & Group 1 & Group 2 & Group 3 & Group 4 \\
\hline BST $^{1}$ before ventilation & pos & neg & neg & neg \\
\hline BST after ventilation & $>1: 5$ & $>1: 5$ & $<1: 5$ & neg \\
\hline$N$ & 3 & 7 & 7 & 4 \\
\hline Gestational age & $138 \pm 2^{2}$ & $134 \pm 3^{2}$ & $124 \pm 1^{4}$ & $118 \pm 2^{4}$ \\
\hline
\end{tabular}

Lung mechanics

$\begin{array}{lllll}\text { VE/VT } & 0.17 \pm 0.02^{2} & 0.19 \pm 0.03^{2} & 0.07 \pm 0.02^{4} & 0^{4} \\ C_{D} / K g & 0.39 \pm 0.05^{2} & 0.40 \pm 0.02^{2} & 0.27 \pm 0.02 & 0.25 \pm 0.03 \\ C_{L} / K g & 1.40 \pm 0.05^{2} & 1.41 \pm 0.06^{2} & 0.86 \pm 0.08 & 0.97 \pm 0.05\end{array}$

Gas Exchange

\begin{tabular}{lcccc}
$\mathrm{PaO}_{2}$ & $191 \pm 46^{2}$ & $206 \pm 25^{2}$ & $81 \pm 22^{4}$ & $18 \pm 2^{4}$ \\
$\mathrm{PaCO}_{2}$ & $43 \pm 5^{2}$ & $30 \pm 2^{2}$ & $51 \pm 4^{4}$ & $84 \pm 9^{4}$ \\
\hline
\end{tabular}

\footnotetext{
' BST, bubble stability test on lung liquid; VE/VT, expiratory volume/total volume by static pressure volume curve; $\mathrm{C}_{\mathrm{D}}$, dynamic compliance during ventilation; $C_{L}$, compliance volume curve calculated from static pressure volume curve.

${ }^{2}$ Different from groups 3 and $4 . P<0.05$.

${ }^{3}$ Mean \pm S.E.

${ }^{4}$ Different from each of other groups. $P<0.05$.
}

Table 2. Lung weights and lung liquid absorption

\begin{tabular}{|c|c|c|c|c|}
\hline & $\begin{array}{c}\text { Group } 1 \\
(3)\end{array}$ & $\begin{array}{l}\text { Group } 2 \\
(7)\end{array}$ & $\begin{array}{l}\text { Group } 3 \\
(7)\end{array}$ & $\begin{array}{c}\text { Group } 4 \\
(4)\end{array}$ \\
\hline $\begin{array}{l}\text { Preventilation } \\
\quad \text { [Alveolar liquid volume }(\mathrm{ml} / \mathrm{kg})]\end{array}$ & $19.9 \pm 1.4^{2}$ & $22.8 \pm 1.0$ & $22.9 \pm 1.6$ & $22.5 \pm 1.7$ \\
\hline $\begin{array}{l}\text { After ventilation } \\
\text { Lung wet wt }(\mathrm{g} / \mathrm{kg}) \\
\text { Lung dry wt }(\mathrm{g} / \mathrm{kg}) \\
\text { Wet:dry ratio }\end{array}$ & $\begin{aligned} 27.3 & \pm 0.1 \\
2.4 & \pm 0.2 \\
11.8 & \pm 1.1^{4}\end{aligned}$ & $\begin{array}{r}25.1 \pm 1.3 \\
2.5 \pm 0.1 \\
10.4 \pm 0.4\end{array}$ & $\begin{aligned} 25.7 & \pm 1.6 \\
2.7 & \pm 0.2 \\
10.0 & \pm 0.5\end{aligned}$ & $\begin{aligned} 32.0 & \pm 2.0 \\
3.1 & \pm 0.2 \\
10.4 & \pm 0.1\end{aligned}$ \\
\hline $\begin{array}{l}\text { Calculated liquid absorption } \\
\text { Volume absorbed }(\mathrm{ml} / \mathrm{kg}) \\
\text { Rate of absorption }(\% / \mathrm{hr})\end{array}$ & $\begin{aligned} 1.1 & \pm 0.8^{4} \\
2 & \pm 1^{4}\end{aligned}$ & $\begin{array}{l}6.7 \pm 0.8 \\
27 \pm 2\end{array}$ & $\begin{aligned} 7.3 & \pm 1.2 \\
27 & \pm 4\end{aligned}$ & $\begin{aligned} 4.7 & \pm 2.0 \\
20 & \pm 8\end{aligned}$ \\
\hline
\end{tabular}

\footnotetext{
${ }^{1}$ Numbers in parentheses, $N$.

${ }^{2}$ Mean \pm S.E.

${ }^{3}$ See "Methods."

${ }^{4}$ Different from each of other groups. $0.05>P<0.01$.
} 
Table 3. Tracer solute absorption

\begin{tabular}{|c|c|c|c|c|}
\hline & $\begin{array}{c}\text { Group } 1 \\
\text { (3) }\end{array}$ & $\begin{array}{c}\text { Group } 2 \\
(7)\end{array}$ & $\begin{array}{c}\text { Group } 3 \\
(7)\end{array}$ & $\begin{array}{l}\text { Group } 4 \\
(4)\end{array}$ \\
\hline Liquid absorption $(\% / \mathrm{hr})$ & $2 \pm 1^{2}$ & $27 \pm 2$ & $27 \pm 4$ & $20 \pm 8$ \\
\hline \multicolumn{5}{|l|}{$\begin{array}{l}\text { Alveolar tracers } \\
\text { (Absorption \%/hr) }\end{array}$} \\
\hline Large (35. .) & $0^{1}$ & $19 \pm 4$ & $31 \pm 13^{2}$ & $18 \pm 11$ \\
\hline Medium (14-17. .) & $3 \pm 1^{2}$ & $53 \pm 3$ & $76 \pm 6^{2}$ & $52 \pm 14$ \\
\hline Small $(5-6)$. & $11 \pm 3^{2}$ & $70 \pm 3$ & $88 \pm 7^{2}$ & $70 \pm 13$ \\
\hline Large & $0^{2}$ & $1.7 \pm 0.2$ & $3.9 \pm 0.5^{2}$ & $1.7 \pm 0.1$ \\
\hline Medium & $0^{2}$ & $22.4 \pm 6.6$ & $73.9 \pm 4.6^{2}$ & $26.3 \pm 16.4$ \\
\hline Small & $0.9 \pm 0.2^{2}$ & $31.1 \pm 12.2$ & $71.1 \pm 8.2^{2}$ & $10.2 \pm 6.6$ \\
\hline
\end{tabular}

Blood Tracer

${ }^{51} \mathrm{CR}$ detected in alveolar liquid

0 of 3

7 of 7

7 of 7

3 of 3

'Numbers in parentheses, $N$.

${ }^{2}$ Mean different from each of other groups $P<0.05$; Specific solutes are identified in "Methods." Mean \pm S.E. Groups are defined in Table 1 .

large solutes moving from lung liquid to blood, and from blood to lung liquid.

There are distinct differences in the relationship between lung liquid absorption and solute absorption among groups 2, 3, and 4 . Animals secreting more surfactant, group 2, absorbed lung liquid volume at a $50 \%$ faster rate than they did the large solute $\left[{ }^{131}\right.$ I] albumin. Animals in both groups 3 and 4 absorbed lung liquid and $\left[{ }^{131} I\right]$ albumin at similar rates. The ratio of $\left[{ }^{131} I\right]$ albumin counts in blood and lung liquid at the end of ventilation parallel the rate of absorption of $\left[{ }^{131} I\right]$ albumin from lung liquid in all groups and serves to confirm the validity of the differences in the calculated rates of $\left[{ }^{131} I\right]$ albumin absorption among the groups. Interpretation of the blood levels of the medium and small tracer solutes after one hr of ventilation is more complex because blood levels reflect not only uptake from the lung liquid and distribution in the extracellular space of the fetus, but also clearance by the kidney.

\section{DISCUSSION}

All 21 fetal animals had biochemically immature lungs by amniotic fluid bubble stability test assay. Despite this immaturity, groups 1 and 2 exchanged oxygen and carbon dioxide effectively and established a residual lung volume independent of chest wall stabilization forces. The presence of significant pulmonary surfactant activity in the remaining alveolar liquid after one hr in these animals reproduces the well-described role of ventilation in surfactant secretion in premature and full-term animals $(2,15,23)$. There is clearly a direct relationship between alveolar lumen surfactant activity and the effectiveness of ventilation in this protocol. It was unexpected that group 2 of these immature goats could secrete enough surfactant to sustain effective gas exchange in the face of a negative bubble stability test on lung liquid. However, it must be emphasized that the total length of ventilation was only one hr. Whether continued ventilation would have been as effective is unknown.

\section{LUNG EPITHELIAL SOLUTE PERMEABILITY}

The epithelium of the fetal lung exhibits a pore radius of 5 to $6 \AA$ for solute movement (20), which increases dramatically during the first hours of breathing before returning to near fetal dimensions (13). Absorption of the fetal liquid from the alveolar space requires transfer of solutes and water from the alveolar space across the epithelium. Increases in epithelial solute permeability are dependent upon the amount of lung inflation in both perinatal and adult animals $(12,13)$.

In the 3 animals in group 1 who had pulmonary surfactant detectable before ventilation, the low-volume ventilation did not produce sufficient lung inflation to increase epithelial permeability enough to allow efflux of $14 \AA$ radius tracers from the alveolar liquid. Their epithelial permeability response was similar to the "low-pressure inflation" experiments previously reported in lambs by Egan et al. (13). The other 3 groups, those with no pulmonary surfactant in fetal lung liquid, all responded to an identical ventilation protocol by altering the lung epithelial permeability so that transfer of all sizes of tracer solutes between blood and lung liquid was easily documented. A similar macromolecular transfer was reported by Normand et al. (21) in immature lambs, although alveolar surfactant was not assayed in fetal lung liquid prior to ventilation.

We suggest that the absence of alveolar surfactant in fetal lung liquid at the initiation of ventilation alters the degree of distention of aerated alveoli during the first breaths. In the absence of surfactant, the surface tension of the alveolar liquid is high and will not vary with inflation. However, the air-gas interface forces opposing inflation are stated by the law of LaPlace as $2 \gamma / r$ where $\gamma$ is surface tension, and $r$ is the radius of the curvature of the airgas interface. If, as a liquid filled, surfactant-deficient alveolus becomes aerated the radius of the air-gas interface increases, the total surface forces opposing further inflation decrease. Furthermore, if the force tending to inflate the lung remains constant, our piston ventilator in these experiments, one would expect that the first terminal air space aerated would be distended to elastic limits before other liquid filled alveoli begin aeration. It is the overdistended alveolar epithelium that changes its barrier properties and allows solutes of all sizes to transfer across it in both directions. Such a pattern of solute movement was observed in all animals devoid of surfactant before ventilation. In contrast, when alveolar surfactant is present before ventilation, surface tension increases during inflation which tends to distribute gas to nonaerated or less well aerated air spaces rather than allowing overdistention of the initially aerated alveolus.

A definitive explanation for the quantitatively larger transfer of solutes out of the alveolar liquid in group 3 than in either group 2 or 4 is lacking. The large amount of pulmonary surfactant released by group 2 animals probably prevented repeated overdistention of air spaces, whereas the total lack of surfactant secretion by group 4 animals and their minimal gas exchange suggests that only a small fraction of the airspaces were ever aerated, limiting the fraction of lung epithelium subjected to distention by gas.

\section{ABSORPTION OF LUNG LIQUID}

The normal time course for absorption of lung liquid is about 5 to $6 \mathrm{hr}(4,10,18)$, although one study in premature animals did not document any decrease in lung weight (2). Our estimates of lung liquid absorption showed that the animals in group 1 exhibited virtually no absorption of alveolar fluid, although the other groups of animals drained approximately one-fourth of the fetal alveolar fluid from the lung during the hour of ventilation. 
The reasons for the minimal liquid absorption in the $\mathbf{3}$ animals in group 1 is consistent with their observed failure to increase the solute permeability of the lung epithelium. The monotonous pattern of constant volume ventilation is different from the initial pattern of ventilation observed in spontaneously breathing newborn lambs. The spontaneously breathing newborn lamb generates 3 to. 6 deep breaths, almost sighs, per min in addition to normal breaths $(10,12)$. We ascribe the minimal lung liquid absorption in the 3 animals in group 1 to the fact that the absence of deep breaths does not inflate air spaces to a volume sufficient to increase lung pore radius normally. Thus, the conductance of the alveolar epithelium to movement of the major solutes of the lung liquid, $\mathrm{Na}^{+}+\mathrm{Cl}^{-}$, is too low to allow liquid absorption to proceed at a normal rate.

The lungs drained fluid at similar rates in all three groups who were without detectable pulmonary surfactant in the lung liquid before breathing. This drainage of the lung liquid was independent of the gas-exchange efficiency of the lung or the release of pulmonary surfactant once ventilation was initiated.

Absorption of lung liquid in this protocol of a monotonous pattern of low tidal volume ventilation was associated with absence of surfactant in alveolar liquid before ventilation and permeability of the alveolar lining to macromolecular solutes. Absorption was measured only at one hr, and it is impossible to determine whether drainage of lung liquid could continue, slow, or even reverse over subsequent hours. Egan et al. (13) speculated that the preservation of an alveolar epithelial barrier to protein movement observed during the first hour of ventilation in spontaneously ventilating mature fetal lambs was important because it maintained the osmotic force generated by the difference in protein concentration between lung interstitial fluid and alveolar fluid for absorption. In these immature fetuses, there was bidirectional protein movement between alveolar and interstitial fluids, and yet, lung liquid absorption occurred. At least for initial lung liquid drainage, an epithelial membrane which prohibits protein flux between alveolar and interstitial spaces is not essential. Whether lung liquid absorption would proceed to completion when the alveolar epithelial membrane is permeable to proteins and the concentration difference between alveolar and interstitial spaces tends to equalize is unknown. We plan additional experiments to clarify this point.

\section{LUNG FUNCTION AND LUNG LIQUID DRAINAGE}

The gas exchange and mechanics of groups 1 and 2 were very similar, but lung liquid drainage rates were very different. In group 1 animals, we were able to aspirate virtually the same amount of liquid from the lung following ventilation as we could before ventilation, and yet, gas exchange was adequate. The volume of fetal liquid in the lung before breathing approximates the functional residual capacity postnatally and is much less than the total volume of the air spaces. The lungs in group 1 contained approximately $20 \mathrm{ml} / \mathrm{kg}$ of air and $20 \mathrm{ml} / \mathrm{kg}$ of liquid at the end of the postmortem pressure volume curve, and presumably such a capacitance for both fluids occurred during the $\mathrm{hr}$ of ventilation, without severe impairment of gas movement in the airway or gas diffusion between alveolus and blood. There is no need to postulate that alveolar liquid must be cleared from the air spaces over a matter of moments to account for development of a functional residual capacity and successful ventilation in a newborn mammal.

In the animals in groups 3 and 4 , lung function was severely impaired, and yet drainage of lung liquid proceeded at a rate similar to that reported in the first hr of spontaneously breathing mature lambs (12). We must emphasize that this project measured only the first hour and strongly suspect that total drainage of the lung liquid would be much delayed if these goats are comparable to human infants dying of respiratory distress (11). However, when comparing the two groups with respiratory insufficiency to animals in group 2, it appears that alveolar surfactant alone and not lung liquid drainage is reponsible for their poor gas exchange, inadequate expiratory lung volumes, and low compliance.

\section{REFERENCES AND NOTES}

1. Abel, S., and Windle, W. F.: Relation of the volume of the pulmonary circulation to respirations at birth. Anat. Rec., 75: 451 (1939).

2. Adams, F. H., Fujiwara, T., and Latta, H.: 'Alveolar' and whole lung phospholipids of premature newborn lambs. Biol. Neonat., 17: 198 (1971).

3. Adams, F. H., Yanagisawa, M., Kuzela, D., and Martinek, H.: The disappearance of fetal lung liquid following birth. J. Pediatr., 78: 837 (1971).

4. Aherne, W., and Dawkins, M. J. R.: The removal of fluid from the pulmonary airways after birth in the rabbit and the effect on this of prematurity and prenatal anoxia. Biol. Neonat., 7: 214 (1964).

5. Avery, M. E., and Cook, C. L. D.: Volume-pressure relationships of lungs and thorax in fetal, newborn and adult goats. J. Appl. Physiol., 10: 1034 (1961).

6. Bland, R. D., McMillan, D. D., and Bressack, M. A.: Movement of water and protein in the fetal and newborn lung. Ann. Rech. Vet., 8: 418 (1977).

7. Boyd, R. D. H., Hill, J. R., Humphreys, P. W., Normand, I. C. S., Reynolds, E. O. R., and Strang, L. B.: Permeability of lung capillaries to macromolecules in foetal and newborn lambs and sheep. J. Physiol. (Lond.), 201: 567 (1969).

8. Carlyle, A.: An integration of the total oxygen consumption of the sheep foetus from that of the tissues. J. Physiol. (Lond.), 107: 355 (1948).

9. Clements, J. A., Platzker, A. C. G., Tierney, D. F., Hobel, C. J., Creasy, R. K., Margolis, A. J., Thibeault, D. W., Tooley, W. H., and Oh, W.: Assessment of the risk of the respiratory distress syndrome by a rapid test for surfactant in amniotic fluid. N. Engl. J. Med., 286: 1077 (1972).

10. Dawes, G. S.: Foetal and Neonatal Physiology. (Yearbook Medical Publishers, Chicago, 1968).

11. DeSa, D. J.: Pulmonary fluid content in infants with respiratory distress. J. Pathol., 97: 469 (1969).

12. Egan, E. A., Nelson, R. M., and Olver, R. E.: Lung inflation and alveolar permeability to non-electrolytes in adult sheep in vivo. J. Physiol. (Lond.), 260: 409 (1976).

13. Egan, E. A., Olver, R. E., and Strang, L. B.: Changes in the non-electrolyte permeability of alveoli and the absorption of lung liquid at the start of breathing in the lamb. J. Physiol. (Lond.), 244: 161 (1975).

14. Gitlin, D. and Craig, J. M.: Nature of the hyaline membrane in asphyxia of the newborn. Pediatrics, 17: 64 (1956).

15. Gluck, L., Montayama, E. K., Smits, H. L., and Kulovick, M. A.: The biochemical development of surfact activity in the mammalian lung. Pediatr. Res., 1: 237 (1967).

16. Hessler, J. R.: A radiographic technique for estimating gestational age in sheep and goats. Lab. Anim. Dig., 8: 69 (1973).

17. Hughes, J. M. B., Glazier, J. B., Maloney, J. E., and West, J. B.: Effect of extraalveolar vessels on the distribution of blood flow in the dog lung. J. Appl. Physiol., 25: 701 (1968).

18. Humphreys, P. W., Normand, I. C. S., Reynolds, E. O. R., and Strang, L. B.: Pulmonary lymph flow and the uptake of liquid from the lungs of the lamb at the start of breathing. J. Physiol. (Lond.), 193: 1 (1967).

19. MacFarland, A. S.: Labeling of plasma proteins with radioactive iodine. Biochem. J., 62: 135 (1956).

20. Normand, I. C. S., Olver, R. E., Reynolds, E. O. R., Strang, L. B., and Welch, K.: Permeability of lung capillaries and alveoli to non-electrolytes in the foetal lamb. J. Physiol. (Lond.), 219: 303 (1971).

21. Normand, I. C. S., Reynolds, E. O. R., and Strang, L. B.: Passage of macromolecules between alveolar and interstitial spaces in foetal and newly ventilated lungs of the lamb. J. Physiol. (Lond.), 212: 151 (1970).

22. Olver, R. E., and Strang. L. B.: Ion fluxes across the pulmonary epithelium and secretion of lung liquid in the fetal lamb. J. Physiol. (Lond.), 241: 327 (1974).

23. Taeush, H. W., Wyszogrodski, I., Wang, N. S., and Avery, M. E.: Pulmonary pressure-volume relationships in premature fetal and newborn rabbits. J. Appl. Physiol., 37: 809 (1974).

24. Walters, D. V., and Olver, R. E.: The role of catecholamines in lung liquid absorption at birth. Pediatr. Res., 12: 239 (1978).

25. The assistance of Mr. Bruce McIntyre and Ms. Mary Blake is gratefully acknowledged.

26. Requests for reprints should be addressed to: Edmund A. Egan, M.D., Children's Hospital, 219 Bryant Street, Buffalo, NY 14222 (USA).

27. This research was supported by NIH Grant HL.22562.

28. Received for publication April 19, 1979.

29. Accepted for publication July $27,1979$. 